\title{
Burnout, Cognitive Overload, and Metacognition in Medicine
}

\author{
Morkos Iskander ${ }^{1,2}$ (D) \\ Published online: 12 November 2018 \\ (C) International Association of Medical Science Educators 2018
}

\section{Introduction}

The number of physicians reportedly suffering from burnout, a phenomenon where the individual appears overwhelmed by tasks usually within their competence, has been increasing internationally $[1,2]$. Burnout represents a large burden for the medical profession, from undergraduate training to the postgraduate world [3-7]. The impact of burnout has effects on physician productivity, although the exact effect remain difficult to quantify [8]. By extension, a physician suffering from burnout is likely to have ramifications to the wider team of colleagues [9]. Evidence suggests that, independent to level of experience, the extent of the relationship between burnout and work extends beyond total capacity and directly affects patient safety [10-12]. The widespread impact on burnout on both the providers and recipients of healthcare is therefore a critical aspect of clinical practice.

Factors affecting the phenomenon of physician burnout have been considered in literature, with reported risk factors being younger age, longer working hours with high workload, low job satisfaction, negative or poor personal relationships and interpersonal demands, job insecurity, and female gender, as well as a weak association with specialty [13-15]. These findings place physicians in common with other healthcare professions [16-18]. However, healthcare professions as a group stand apart as particularly prone to burnout $[5,19]$. The implication of this suggests that risk factors are shared within the healthcare professions. This may also imply that risk reduction and prevention strategies can be applied across the spectrum. Prior to considering the prevention, it is invaluable to evaluate the stressors associated with healthcare that serve to predispose these professions to burnout.

Morkos Iskander

morkos.iskander@doctors.org.uk

1 Department of Educational Research, Faculty of Social Sciences, Lancaster University, Lancaster, UK

2 Health Education North West, Liverpool, Merseyside, UK

\section{Burnout in the Medical Workforce}

An increasing body of evidence suggests that the emotional burden of working in healthcare is directly linked to the higher risk of burnout compared to the general population [20-22]. This is further supported by comparative studies that have connected the level of psychological stress and related emotional load to burnout, demonstrating a linear correlation between them [23, 24]. The link between burnout and depression has been widely debated in literature, with consensus being difficult to attain. Nevertheless, while the symptom cluster of depression and burnout tend to overlap, sometimes significantly, distinction between the two is possible [25-29]. It is clear from the evidence that the depression and burnout are connected conditions, which may coexist in a single physician. However, establishing the distinction between them may prove invaluable to direct care and support as required.

Recently, evidence for burnout as a distinct clinical entity has emerged from neuroscience. It has been demonstrated that individuals suffering from burnout exhibited a diminished neurophysiological responses to stimuli compared to control subjects [30]. Further studies examining the evoked responses to stimuli across sensory modalities have indicated intact pathways at the sensory level, although a comparative deficit exists at the point of directing attention [31,32]. However, the deficit is situated at the level of performance at tasks, and did not appear to be focused on a particular cognitive process [33]. It is therefore possible to extrapolate that the core symptomology of burnout does not lie in memory subtypes, from sensory memory through working memory and longterm memory. Rather, the functional deficit is situated at the nexus of metacognition.

\section{Cognition and Metacognition in Burnout}

By utilizing the theoretical framework of cognitive load theory, it is possible to gain an insight into the phenomenon of burnout, and how this affects the individual physician. Cognitive load theory [CLT] argues that task completion relies 
on the complex interplay between sensory inputs, long-term memory acting as a repository of acquired knowledge and skills, with working memory as the intermediate stage, acting to attribute meanings to the sensory information, and deposit new learned information into the long-term memory [34]. However, while both sensory and long-term memories are capable of dealing with large volumes of information, the capacity of working memory is comparatively very limited $[35,36]$. Cognitive overload is presumed to occur when this capacity is exceeded, requiring the individual to co-ordinate a larger than possible number of elements to accomplish tasks successfully. Dictating the direction of working memory is the individual's attention or metacognitive capacity, guiding working memory to relevant sensory information, as well as appropriate knowledge or schemas in the long-term memory, as well as directing the learning process [37].

The value of appreciating the role of attention in managing the function of working memory has been highlighted in several studies, indicating that the value added by engaging attention leads to a higher degree of performance [38, 39]. Following this line of argument, a physician approaching the point of cognitive overload may begin to exhibit symptoms similar to depressive symptoms, with the addition of deterioration in quality or quantity of work, relative to their own previous standard. While the current understanding of depression is a prolonged affective state of hopelessness and diminished functionality, without a clear triggering point, the phenomenon of burnout may be distinguished as a self-protective neuropsychological response to attempting to function beyond a fixed capacity. Both depression and burnout can however result in a reduced ability to function effectively at the normal baseline.

Metacognition functions as a method for continuously reevaluation, bridging and coordinating the different aspects of memory function, and therefore directing attention [40]. It is defined as the dynamic skill and judgment regarding the individual's knowledge as applied to current situations. From this vantage point, it is evident that the executive role of metacognition in learning continues beyond the acute phase of experience, and into the construction of schema within the long-term memory [41]. It is significant to note recent systematic reviews and meta-analyses concluded that attempting to enhance the capacity or function of working memory in healthy individuals does not result in significant levels of improvement [42, 43], compared to metacognition, which is more akin to a skill, and thus may be improved with training [44, 45]. Consequently, developing metacognitive skills to a higher level will afford the ability to manage cognitive load more effectively.

\section{Conclusions}

Cognitive load represents the overall burden experienced by an individual, as a sum of the various sensory, task-specific demands, as well as the psychological and emotional factors faced. It can be deduced that as occupational complexity and demands increase, with coinciding rise in the emotive strains, the total load placed on individuals rises. The relationship between each aspect of life and the total load, rather the cumulative effect of professional and personal stresses may be exponential. For physicians, where professional demands are consistently high, the tolerance for additional loads is likely to be consistently lower than that for non-physicians. This effect is further compounded by physicians being emotionally invested in the profession and professional identity. In combination, once these stresses reach the level of cognitive load capacity and exceed it, the physician in question is may be expected to exhibit the symptoms of cognitive overload.

While the symptoms may vary, they can include increased rate of errors, inability to carry out activities to a similar competence as achieved previously, or a more subtle signs such as a deterioration in intrapersonal and communication skills. Reaching the point of cognitive overload is therefore likely to be the immediate precedent of burnout. This may therefore allow for anticipation of burnout, with adequate supportive interventions instigated.

An individual's capacity for cognitive load is fixed, and not amenable to change. We must therefore address burnout from different angles. While it is not practicable to manage a physician's personal life, we can deduce that the professional capability is liable to extensive training. Additionally, the provision of supported practice environments, such that the physician is not tasked unsupported with clinical situation beyond their current competence, would also be protective against cognitive overload. Specific training may be beneficial for improving metacognition, and thus provide physicians with the skill set to minimize the risk of cognitive overload and subsequent burnout, tailored to individual practice. It is therefore imperative to begin specific training targeting metacognition and resilience for medical students, and continue the program throughout the postgraduate training and beyond.

Finally, we as a profession have a duty of care to our colleagues as well as our patients to guard against physician burnout. As its symptoms are appreciated we will be in a position to act as support for our colleagues, recognizing when they are approaching the point of cognitive overload and instituting strategies to assist them. This can only serve to safeguard our patients and act to protect the profession as a whole.

\section{Compliance with Ethical Standards}

Conflicts of Interest The author confirms that he has no conflict of interest.

Ethical Approval NA

Informed Consent NA 


\section{References}

1. Lee YY, Medford ARL, Halim AS. Burnout in physicians. J R Coll Physicians Edinb. 2015;45(2):104-7. https://doi.org/10.4997/jrcpe. 2015.203.

2. Al-Dubai SA, Rampal KG. Prevalence and associated factors of burnout among doctors in Yemen. J Occup Health. 2010;52(1): 58-65.

3. Arora M, Asha S, Chinnappa J, Diwan AD. Review article: burnout in emergency medicine physicians. Emerg Med Australas. 2013;25(6):491-5. https://doi.org/10.1111/1742-6723.12135.

4. Cruz OA, Pole CJ, Thomas SM. Burnout in chairs of academic departments of ophthalmology. Ophthalmology. 2007;114(12): 2350-5.e1. https://doi.org/10.1016/j.ophtha.2007.04.058.

5. Dyrbye L, Shanafelt T. A narrative review on burnout experienced by medical students and residents. Med Educ. 2016;50(1):132-49. https://doi.org/10.1111/medu.12927.

6. Ishak W, Nikravesh R, Lederer S, Perry R, Ogunyemi D, Bernstein C. Burnout in medical students: a systematic review. Clin Teach. 2013;10(4):242-5. https://doi.org/10.1111/tct.12014.

7. Johns MM, Ossoff RH. Burnout in academic chairs of otolaryngology: head and neck surgery. Laryngoscope. 2005;115(11):2056-61. https://doi.org/10.1097/01.Mlg.0000181492.36179.8b.

8. Dewa CS, Loong D, Bonato S, Thanh NX, Jacobs P. How does burnout affect physician productivity? A systematic literature review. BMC Health Serv Res 2014;14(1). doi:https://doi.org/10. 1186/1472-6963-14-325.

9. Ochoa P. Impact of burnout on organizational outcomes, the influence of legal demands: the case of Ecuadorian physicians. Front Psychol 2018;9. doi:https://doi.org/10.3389/fpsyg.2018.00662.

10. Dewa CS, Loong D, Bonato S, Trojanowski L. The relationship between physician burnout and quality of healthcare in terms of safety and acceptability: a systematic review. BMJ Open. 2017;7(6):e015141. https://doi.org/10.1136/bmjopen-2016015141.

11. Dewa CS, Loong D, Bonato S, Trojanowski L, Rea M. The relationship between resident burnout and safety-related and acceptability-related quality of healthcare: a systematic literature review. BMC Med Educ 2017;17(1). doi:https://doi.org/10.1186/ s12909-017-1040-y.

12. Lu D, Dresden S, McCloskey C, Branzetti J, Gisondi M. Impact of burnout on self-reported patient care among emergency physicians. West J Emerg Med. 2015;16(7):996-1001. https://doi.org/10.5811/ westjem.2015.9.27945.

13. Azam K, Khan A, Alam MT. Causes and adverse impact of physician burnout: a systematic review. J Coll Physicians Surg Pak. 2017;27(8):495-501.

14. Amoafo E, Hanbali N, Patel A, Singh P. What are the significant factors associated with burnout in doctors?: table 1. Occup Med. 2015;65(2):117-21. https://doi.org/10.1093/occmed/kqu144.

15. Vicentic S, Gasic MJ, Milovanovic A, Tosevski DL, Nenadovic M, Damjanovic A, et al. Burnout, quality of life and emotional profile in general practitioners and psychiatrists. Work. 2013;45(1):12938. https://doi.org/10.3233/WOR-121484.

16. Gillespie M, Melby V. Burnout among nursing staff in accident and emergency and acute medicine: a comparative study. J Clin Nurs. 2003;12(6):842-51.

17. Khamisa N, Peltzer K, Oldenburg B. Burnout in relation to specific contributing factors and health outcomes among nurses: a systematic review. Int J Environ Res Public Health. 2013;10(6):2214-40. https://doi.org/10.3390/ijerph10062214.

18. Kalliath T, Morris R. Job satisfaction among nurses: a predictor of burnout levels. J Nurs Adm. 2002;32(12):648-54.

19. Tremolada M, Schiavo S, Tison T, Sormano E, De Silvestro G, Marson P, et al. Stress, burnout, and job satisfaction in 470 health professionals in 98 apheresis units in Italy: a SIdEM collaborative study. J Clin Apher. 2015;30(5):297-304. https://doi.org/10.1002/ jca.21379.

20. West CP, Dyrbye LN, Satele DV, Sloan JA, Shanafelt TD. Concurrent validity of single-item measures of emotional exhaustion and depersonalization in burnout assessment. J Gen Intern Med. 2012;27(11):1445-52. https://doi.org/10.1007/s11606-0122015-7.

21. Bartram T, Casimir G, Djurkovic N, Leggat SG, Stanton P. Do perceived high performance work systems influence the relationship between emotional labour, burnout and intention to leave? A study of Australian nurses. J Adv Nurs. 2012;68(7):1567-78. https://oi.org/10.1111/j.1365-2648.2012.05968.x.

22. Kovács M, Kovács E, Hegedüs K. Is emotional dissonance more prevalent in oncology care? Emotion work, burnout and coping. Psycho-Oncology. 2009;19(8):855-62. https://doi.org/10.1002/ pon.1631.

23. Chuang C-H, Tseng P-C, Lin C-Y, Lin K-H, Chen Y-Y. Burnout in the intensive care unit professionals. Medicine. 2016;95(50):e5629. https://doi.org/10.1097/md.0000000000005629.

24. Garcia TT, Garcia PCR, Molon ME, Piva JP, Tasker RC, Branco $\mathrm{RG}$, et al. Prevalence of burnout in pediatric intensivists. Pediatr Crit Care Med. 2014;15(8):e347-e53. https://doi.org/10.1097/pcc. 0000000000000218.

25. Hills RK, Montero-Marin J, Zubiaga F, Cereceda M, Piva Demarzo MM, Trenc P, et al. Burnout subtypes and absence of selfcompassion in primary healthcare professionals: a cross-sectional study. PLoS One. 2016;11(6):e0157499. https://doi.org/10.1371/ journal.pone.0157499.

26. Bianchi R, Schonfeld IS, Laurent E. Is burnout separable from depression in cluster analysis? A longitudinal study. Soc Psychiatry Psychiatr Epidemiol. 2014;50(6):1005-11. https://doi. org/10.1007/s00127-014-0996-8.

27. Thalhammer M, Paulitsch K. Burnout - eine sinnvolle Diagnose? Kritische Überlegungen zu einem populären Begriff. Neuropsychiatrie. 2014;28(3):151-9. https://doi.org/10.1007/ s40211-014-0106-x.

28. Reime B, Steiner I. Ausgebrannt oder depressiv? - Eine empirische Studie zur Konstruktvalidität von Burnout in Abgrenzung zur Depression. PPmP - Psychotherapie Psychosomatik Medizinische Psychologie. 2001;51(8):304-7. https://doi.org/10.1055/s-200115996.

29. van Wouwe J, Wurm W, Vogel K, Holl A, Ebner C, Bayer D et al. Depression-burnout overlap in physicians. PLoS One 2016;11(3). doi:https://doi.org/10.1371/journal.pone.0149913.

30. Golonka K, Mojsa-Kaja J, Popiel K, Marek T, Gawlowska M. Neurophysiological markers of emotion processing in burnout syndrome. Front Psychol 2017;8. doi:https://doi.org/10.3389/fpsyg. 2017.02155.

31. Bianchi R, Laurent E. Emotional information processing in depression and burnout: an eye-tracking study. Eur Arch Psychiatry Clin Neurosci. 2014;265(1):27-34. https://doi.org/10.1007/s00406-0140549-x.

32. Sokka L, Huotilainen M, Leinikka M, Korpela J, Henelius A, Alain $\mathrm{C}$, et al. Alterations in attention capture to auditory emotional stimuli in job burnout: an event-related potential study. Int $\mathrm{J}$ Psychophysiol. 2014;94(3):427-36. https://doi.org/10.1016/j. ijpsycho.2014.11.001.

33. Golonka K, Mojsa-Kaja J, Gawlowska M, Popiel K. Cognitive impairments in occupational burnout - error processing and its indices of reactive and proactive control. Front Psychol 2017;8. doi:https://doi.org/10.3389/fpsyg.2017.00676.

34. Sweller J. Cognitive load theory. Psychology of learning and motivation. Elsevier; 2011. p. 37-76.

35. Cowan N. Metatheory of storage capacity limits. Behav Brain Sci. 2001;24(1):154-76. 
36. Mathy F, Feldman J. What's magic about magic numbers? Chunking and data compression in short-term memory. Cognition. 2012;122(3):346-62. https://doi.org/10.1016/j. cognition.2011.11.003.

37. Kirschner PA. Cognitive load theory: implications of cognitive load theory on the design of learning. Learn Instr. 2002;12(1):1-10. https://doi.org/10.1016/S0959-4752(01)00014-7.

38. Chow M, Conway ARA. The scope and control of attention: sources of variance in working memory capacity. Mem Cogn. 2015;43(3):325-39. https://doi.org/10.3758/s13421-014-0496-9.

39. Shipstead Z, Harrison TL, Engle RW. Working memory capacity and the scope and control of attention. Atten Percept Psychophys. 2015;77(6):1863-80. https://doi.org/10.3758/s13414-015-0899-0.

40. Nelson TO, Narens L. Why investigate metacognition. In: Shimamura JMAP, editor. Metacognition: Knowing about knowing. 1994. p. 1-25.

41. Nelson TO, Narens L, Dunlosky J. A revised methodology for research on metamemory: pre-judgment recall and monitoring (PRAM). Psychol Methods. 2004;9(1):53-69. https://doi.org/10. 1037/1082-989x.9.1.53.
42. Melby-Lervåg M, Hulme C. Is working memory training effective? A meta-analytic review. Dev Psychol. 2013;49(2):270-91. https:// doi.org/10.1037/a0028228.

43. Melby-Lervåg M, Redick TS, Hulme C. Working memory training does not improve performance on measures of intelligence or other measures of "far transfer". Perspect Psychol Sci. 2016;11(4):51234. https://doi.org/10.1177/1745691616635612.

44. Stark R, Mandl H, Gruber H, Renkl A. Conditions and effects of example elaboration. Learn Instr. 2002;12(1):39-60. https://doi.org/ 10.1016/S0959-4752(01)00015-9.

45. Scott BM, Schwartz NH. Navigational spatial displays: the role of metacognition as cognitive load. Learn Instr. 2007;17(1):89-105. https://doi.org/10.1016/j.learninstruc.2006.11.008.

\section{Publisher's Note}

Springer Nature remains neutral with regard to jurisdictional claims in published maps and institutional affiliations. 